\title{
INFECTIOUS DISEASE NOTIFICATION — PROGRESS AT LAST
}

\section{TABLE 2}

CONDITIONS TO BE NOTIFIED BY DOCTORS AND HOSPITAL CHIEF EXECUTIVE OFFICERS

- Acquired immunodeficiency syndrome (AIDS) Acute viral hepatitis

Adverse event following immunisation

Foodborne illness in two or more related cases

Gastroenteritis among people of any age, in an institution (e.g. among people in educational or residential institutions)

Leprosy

Measles*

Pertussis (Whooping cough)

Syphilis

Tuberculosis

\section{CONDITIONS TO BE NOTIFIED BY LABORATORIES}

Arboviral infections

Brucellosis

Cholera*

Diphtheria

Gonorrhoea

Haemophilus influenzae type b (blood or

cerebrospinal fluid only)*

Hepatitis A

Hepatitis B

Hepatitis C

Hepatitis D (Delta)

Hepatitis E

Human immunodeficiency virus (HIV) infection Legionella infections

Leptospirosis

Listeriosis

Malaria

Meningococcal infections* (blood or cerebrospinal fluid only)

Mumps

Mycobacterial infections

Pertussis

Plague*

Q fever

Rubella

Salmonella infections

Syphilis

Typhus (epidemic)*

Viral haemorrhagic fevers*

Yellow fever*

\section{ADDITIONAL CONDITIONS TO BE NOTIFIED BY} HOSPITAL CHIEF EXECUTIVE OFFICERS

\section{Cholera*}

Diphtheria

Haemophilus influenzae type b:

epiglottitis*

meningitis*

septicaemia*

Hydatid disease

Legionnaires' disease*

Meningococcal disease:

meningitis*

septicaemia*

Paratyphoid

Plague*

Poliomyelitis

Tetanus

Typhoid

Typhus (epidemic)*

Viral haemorrhagic fevers*

Yellow fever*

To be notified by telephone to Public Health Units

\section{INTRODUCTION}

nfectious disease notification has been required under

legislation in NSW since $1902^{1}$. However, schedules of notifiable diseases have often been anachronistic and compliance has been poor ${ }^{2}$, because the relevance of notification to disease control has not been evident to clinicians. The schedules have comprised long lists of conditions, some of which have had no public health significance (e.g. ornithosis and ankylostomiasis), and they have omitted conditions for which a public health response is essential (e.g. Haemophilus influenzae type b). Also, health departments in Australia have lacked protocols for diseases which require prompt public health action.

This article describes new approaches to infectious disease surveillance and control in NSW. The example of a measles outbreak highlights the importance of collaboration between clinicians and the new public health network which has been established in the State.

\section{PUBLIC HEALTH DEVELOPMENTS}

The NSW Health Department re-established an Epidemiology Branch in 1989 and supported the development of 14 Public Health Units (PHUs) throughout the State. The PHUs have wide responsibilities in monitoring health on an Area and Regional basis, implementing prevention measures and responding to public health problems. The specific responsibilities of the PHUs, in relation to infectious diseases, are surveillance (including laboratory, hospital and clinician notifications) and implementation of effective and timely responses to limit the spread of infectious diseases of public health importance within the community. These responses not only reduce morbidity and mortality from infectious diseases, but result in substantial saving on treatment (antibiotics, hospital beds, intensive care and health care personnel).

A new Public Health Act, proclaimed in November 1991, has rationalised infectious disease notification, so that only those conditions requiring a public health response are notifiable. These diseases are listed in Table 2.

\section{AN INFECTIOUS DISEASE PROBLEM}

Throughout 1990 and continuing into 1991, public health officials in at least four States and Territories NSW, Victoria, the ACT and the Northern Territory received unusually large numbers of measles notifications.

In the event of a measles epidemic, public health practice requires a prompt response to prevent its propagation in the community ${ }^{3}$. It is generally accepted that all susceptible contacts must be immunised within 72 hours of exposure if they are to be protected, because the "incubation period" of the live vaccine is three days less than that of the native virus. However, the practical problems militating against this deadline are formidable. 


\section{Progress at last}

\section{THE PUBLIC HEALTH UNITS' PERSPECTIVE}

T here is something special about working with the infectious diseases notifications in a Public Health Unit. To many the task may seem dull, boring and repetitious but for those who take up the challenge life is never dull. In most PHUs this job has become the "cross" of the Public Health Nurse.

With the enactment in November 1991 of the new Public Health Act the more streamlined process of the notification of infectious diseases began formally. Doctors and laboratories received their colour-coded packages containing the infectious diseases notification forms that month. For many laboratories the notification system was a new process and its implementation appeared to occur without too many problems.

Staff of the PHUs spent many hours educating doctors on the new system. The biggest challenge in this process was convincing a doctor's receptionist that you needed to talk to the doctor and that tomorrow would not do. The reward was hearing the surprised tone in the doctor's voice when he or she realised someone was interested in the case of measles being notified and that the bottomless black hole that devoured notifications in the past no longer existed.

Notifications arrive in the PHUs by phone or mail. For those PHUs that act as a distribution centre for the private laboratories, the arrival of the mail is viewed with dread. Murphy's law says that as soon as you put one batch of sorted notifications in the mail another will arrive for processing.

The worst time for a notification is $4.45 \mathrm{pm}$ on a Friday before a long weekend. The phone rings and someone wants to notify a case of Haemophilus influenzae type b or measles. All thoughts of leaving work on time to beat the holiday traffic vanish as you put down the phone and begin madly turning the pages of the Infectious Diseases Manual in an attempt to salvage something of the weekend.

As the public becomes aware of the services provided by the Public Health Units, the number of calls about all diseases - whether notifiable or not - is increasing. Schools require information about "nits", nursing homes ask for help with outbreaks of scabies, and day care centres need help in developing infection control policies.

Information sharing on the problems experienced with the notification system takes place at gatherings such as the Public Heaith Nurses' quarterly meetings and the Infectious Diseases Special Interest Group. These forums enable all units to have input into changes that may need to be made to the system.

The notification of infectious diseases is an evolving process.

Desolie Lovegrove - Illawarra Area Public Health Unit. Gay Rixon-Northern Sydney Area Public Health Unit.

\section{Continued from page 53}

One of the most important delaying factors is difficulty with the diagnosis of what has become a rare condition. Although laboratory diagnosis of measles is both sensitive and specific, there is general reluctance to subject children to venipunctures.

Once a presumptive diagnosis is made, prompt notification of the case to the local PHU is essential. In the past, compliance with measles notification regulations has been estimated to be about 3 per cent ${ }^{5}$. Measles is highly contagious. The combination of poor notification rates and high infectivity leads to rapid spread, rendering a local response to the outbreak ineffective.

In April 1991, just before the Easter long weekend, the NSW Health Department's Epidemiology and Health Services Evaluation Branch was notified of 46 measles cases in the Northern and Central Sydney Areas. One of these cases had been identified in a boarding school which was about to close for the Easter holidays. The preferred response to such a notification is an immunisation campaign within the school, but because students were dispersing throughout the State this was not feasible. To alert parents to the potential threat of measles the Health Department issued a media release, and this attracted much public attention, associated with a great increase in measles vaccine utilisation. Clinical services, including those in public hospitals, were unprepared for the demands this created.

Measles outbreaks such as those in 1991 suggest that while the improved notification and response arrangements may improve infectious disease control, a paradoxical increase in the number of notifications may occur.

Before the establishment of PHUs, in 1990, public health responses to infectious diseases occurred on an ad hoc basis. Outbreaks which may have occurred in the past but did not attract attention will now evoke an appropriate response. The measles outbreak provided a relatively straightforward test of the new public health arrangements and the capacity of clinical services to deal with the consequences. A harder test would be the introduction into Australia of an exotic disease, e.g. a viral haemorrhagic fever.

\section{THE PUBLIC HEALTH RESPONSE}

The NSW Health Department has devised a set of response protocols for notifications which has been distributed to all PHUs? The protocols specify the public health action required for the response to each notifiable condition. After each notification, the clinician receives a report of the action taken, and can be assured that the appropriate response has been implemented.

The public health network does not operate in isolation from clinical medicine. Clinicians have a responsibility to the community in which they practise, beyond the individual patient. Notification of a scheduled infectious disease should be seen as an integral part of the clinical care of a patient. It has been suggested that by not 


\section{INFECTIOUS DISEASES}

notifying, doctors expose themselves to civil action for negligence by the people who subsequently contract the potentially preventable disease.

Several steps could be taken to improve notification of infectious diseases.

- Undergraduate and postgraduate curricula for clinical studies must emphasise the importance of infectious disease surveillance and the role of disease notification within a comprehensive health care system.

Health departments must inform clinicians of the relevance of notification, both for the individual patient and for the community. Efforts must be made to improve the timeliness and accuracy of infectious disease diagnosis. Clinicians should notify presumptive cases following clinical diagnosis. Where clinical diagnosis is uncertain, clinicians are encouraged to undertake appropriate confirmatory tests; if the public health response cannot await laboratory confirmation, an epidemiological case definition can be used to guide public health action.

The health system in NSW must devise a public health contingency plan to deal with problems of public health significance. Area Health Services have a statutory obligation to "promote, protect and maintain" the health of their resident population (Area Health Services Act 1987). Collaboration between clinicians and the public health network could be enhanced at a local level by the formation of health action groups. These could include representatives of hospitals, primary health care providers, Public Health Units, community health services, and health consumer groups.

Michael H Levy,

Manager, Infectious Diseases Section, Epidemiology and Health Services Evaluation Branch.

Bin Jalaludin,

Deputy Medical Officer of Health, Western Sector Public Health Unit.

\section{Christine Roberts,}

Public Health Officer, Epidemiology and Health Services Evaluation Branch.

1. Public Health Act and Regulation 1991.

2. Levy MH, Manning W, Rubin GL. Bacterial meningitis makes a comeback. NSW Public Health Bulletin 1991; 2:8-10.

3. Report of the Committee on Infectious Diseases. American Academy of Pediatrics. Mlinois. 22nd Edition. 1991.

4. Mandell GL, Douglas RG, Bennett JE. Principles and Practice

of Infectious Diseases. Churchill Livingstone. New York. 1990.

of Infectious Diseases. Churchill Livingstone. New York. 1990 .

5. Dunstone $M$. The common infectious diseases in Australia - a report from the Australian general practitic
survey. Med .J Aust 1976; 1:57-60.

6. Taylor L. Catching a measles outbreak. NSW Public Health Bulletin $1990 ; 2: 65,69$

7. Infectious Disease Manual. Epidemiology and Health Services

Evaluation Branch, NSW Health Department. Sydney. 1991.

\section{REPORTING STATISTICS}

ata in this Bulletin relate to Epiweeks 1 to 17. The following table lists the number of weekly reports made to the Epidemiology and Health Services Evaluation Branch this year, out of a possible 16 .

\section{TABLE 3}

NUMBER OF WEEKLY REPORTS MADE TO EPIDEMIOLOGY BRANCH - 1992

\begin{tabular}{|l|c|l|}
\hline Public Health Unit & Number & Status \\
\hline Central/Southern Sydney & 12 & Complete \\
Eastern Sydney & 5 & Last return April 7 \\
South Western Sydney & 7 & Last return March 4 \\
Western Sector & 16 & Complete \\
Northern Sydney & 16 & Complete \\
Central Coast & 7 & Last return April 9 \\
Illawarra & 12 & Complete \\
Hunter & 11 & Complete \\
North Coast & 14 & Last return April 23 \\
New England & 14 & Complete \\
Orana and Far West & 16 & Complete \\
Central West & 11 & Complete \\
South-West & 16 & Complete \\
South-East & 16 & Complete \\
\hline
\end{tabular}

\section{TABLE 4}

PERCENTAGE OF NOTIFICATIONS WITH INCOMPLETE INFORMATION BY VARIABLE AND PUBLIC HEALTH UNIT, JANUARY-APRIL 1992.

\begin{tabular}{|l|c|c|c|}
\hline Public Health Unit & Age & Sex & Aboriginality \\
\hline Central/Southern Sydney & 1.3 & Complete & 100.0 \\
Eastern Sydney & 9.4 & 6.8 & 100.0 \\
South Western Sydney & 4.0 & 4.6 & 78.8 \\
Western Sydney & 7.8 & 8.1 & 94.4 \\
Wentworth & 6.7 & 5.3 & 94.7 \\
Northern Sydney & 3.0 & 3.0 & 100.0 \\
Central Coast & 2.0 & 2.0 & 100.0 \\
Illawarra & 3.0 & 1.0 & 94.0 \\
Hunter & 2.9 & 1.5 & 99.7 \\
North Coast & 1.8 & 1.5 & 90.1 \\
New England & 30.7 & 11.0 & 87.2 \\
Orana and Far West & 5.0 & Complete & 85.4 \\
Central West & 4.0 & Complete & 94.0 \\
South-West & Complete & Complete & 80.6 \\
South-East & 1.9 & 3.9 & 72.5 \\
\hline
\end{tabular}

\section{LEGIONNAIRES' DISEASE OUTBREAK}

Staff from South Western Sydney and other Public Health Units and the Epidemiology Branch responded to a large outbreak of Legionnaires' disease centred on the Fairfield area in South-West Sydney.

A case control study was undertaken. The case definition was:

- Definite: Positive serology culture or direct immunofluorescence stain of involved tissue or respiratory secretions for legionella.

Probable: All the following criteria had to be met:

- Illness of $<$ two weeks duration

- aged $>20$ years,

- no alternative microbiological diagnosis,

- chest x-ray signs of pneumonia - infiltrate/ opacity, or laboratory evidence of hypoxia $\left(\mathrm{p}_{\mathrm{a}} \mathrm{O}_{2}<85 \mathrm{~mm}\right)$;

In addition, two or more of the following criteria had to be met:

- gastrointestinal symptoms,

- central nervous system symptoms/signs,

- history of heavy smoking,

- immunosuppression,

- myalgia,

- prostration, 